\title{
P-1194 - HOW TO REDUCE SELF-STIGMA IN SCHIZOPHRENIA? - AN INTERVENTION THROUGH SOCIODRAMA AND E-LEARNING
}

\section{S.D.Sousa, A.J.Marques, C.Queirós}

${ }^{1}$ Serviço de Psiquiatria, Hospital de S. João, E.P.E., ${ }^{2}$ Laboratório de Reabilitação Psicossocial, Faculdade de Psicologia e de Ciências da Educação da Universidade do Porto e Escola Superior de Tecnologia da Saúde do Instituto Politécnico do Porto, Porto, Portugal

Introduction: Self-stigma is a personal response to perceived mental illness stigma (Corrigan \& Watson, 2002). Applying recovery to persons with mental illnesses such as schizophrenia, implies working with Self-Stigma, in the sense that is one of the major obstacles to social integration and to active life (Brohan et al., 2011; Corrigan \& Kleinlein, 2005; Goffman, 1991). Research on strategies for changing self-stigma can be focus on new and innovative programs, like the one we will present, based on group intervention (sociodrama) and individual intervention (e-learning).

Aims: To describe results of a 4 months anti-self-stigma program, developed to reduce self-stigma in persons with schizophrenia.

Methods: Data collected with portuguese versions of Helpful Aspects of Therapy Form (Llewelyn, 1988; Elliott, 1993; Sales et al., 2007), Change Interview - FIT (Elliott, 1999; Sales et al., 2007), Internalized Stigma of Mental Illness Inventory (Ritsher et al., 2003; Oliveira \& Gonçalves Pereira, 2008) and CORE-OM (C) CORE System Trust (1995; Sales et al., 2007), with 17 persons with schizophrenia (15 male and 2 female; mean age 38; mean years of disease 15) followed in a psychiatric department. The program includes, beside the 15 e-learning sessions, 15 weekly sessions of sociodrama.

Results: Main changes imply decrease in self-stigma, better interpersonal relationships, more knowledge about mental illness, and better cope with social anxiety and more subjective well-being. Conclusions: This program is an approach that seems to empower persons with schizophrenia, allowing them to achieve significant changes, promoting reduction of self-stigma. 